\title{
Dossiê Saúde
}





\title{
Os desafios para a saúde
}

\author{
JOSÉ R. CARVALHEIRO
}

\section{Retorno à casa paterna}

$\mathrm{O}$ MUNDO CONTEMPORÂNEO assiste a uma dramática deterioração das condições gerais de vida e saúde de segmentos cada vez maiores da população. Uma agenda de discussões carregada faz parte do repertório de teóricos, políticos, empresários e trabalhadores; enfim, de toda a população. Uma ampla diversidade dessa agenda torna difícil identificar a importância relativa de cada um dos grandes temas atualmente em debate, tanto no Brasil quanto (especialmente) no exterior. Não passa despercebido, no entanto, o crescente interesse pelo que está ocorrendo na área. As razões mais evidentes a justificar esse interesse, poderiam ser de natureza humanitária, diante da vergonhosa situação da saúde em grande parte do mundo. Quando se fala nisso pensamos logo no continente africano, ao sul do Saara. Mas a gravidade da situação se revela até mesmo nos EUA, potência hegemônica, onde proporção elevada da população, estimada em aproximadamente 40 milhões de pessoas, vive à margem da assistência médica. Onde, apesar da imensa sofisticação do aparato de atendimento direto às pessoas doentes, as chamadas práticas alternativas ocupam um lugar cada vez mais visível.

Que se passa no mundo, no que diz respeito à saúde? Quando a saúde é vista mais de perto, em seu desenvolvimento recente, verifica-se que a principal razão da repentina importância nada tem de humanitário. Trata-se de uma ênfase de natureza econômica. A saúde deixou de ser apenas uma atividade no âmbito do social, destinada à proteção da higidez dos sadios e a recuperação e reabilitação de doentes e lesionados. Num momento da história da humanidade em que o setor terciário da economia é o que mais tem crescido enquanto processo de acumulação, a área da saúde é de todas a mais dinâmica. Pela incorporação tecnológica desabrida e pela mudança substancial dos processos de gestão das atividades do setor: especialmente da assistência médica individual às pessoas, cada vez mais cara e exercida por prestadores privados.

A situação internacional exige um posicionamento cada vez mais definido quanto à exclusão social. Em particular, sobressai a questão do acesso aos bens e serviços de saúde; a qualidade, a eqüidade e a ética nas ações de saúde, sua distribuição e suporte financeiro. As perspectivas do agrava- 
mento da crise do sistema financeiro internacional e seus reflexos na área social em geral e da saúde em particular têm sido motivo de preocupação de diversos autores. Citamos, em particular, Giovanni Berlinguer, editor da revista Qualità/Equità (Berlinguer, 1996) e autor de artigo neste Dossiê Saúde (Berlinguer, 1999).

O livro de Medicina Social de McKeown \& Lowe (1968) pode ser considerado uma espécie de clássico contemporâneo. Contribuiu para a formação da maioria dos sanitaristas da atualidade em todo o mundo. É dividido em três partes que tratam, sucessivamente, de problemas, métodos e serviços. Mostra como se identificam os problemas de saúde, se formulam propostas de solução e se criam organizações na sociedade destinadas à aplicação das medidas propostas para resolver os problemas. Em todos esses aspectos existe controvérsia. É importante não negligenciar a capacidade dos diversos grupos sociais em erigir como magnos os seus problemas.

De qualquer forma, problematizar necessidades é um dos pontos mais controversos no atual quadro da saúde pública em todo o mundo. As receitas que aparecem com muita freqüência são sempre dirigidas aos países subdesenvolvidos. Há uma tendência crescente de inventar métodos simplificados para apreensão da realidade dos pobres, em suas próprias comunidades. As técnicas de estimativas rápidas, muitas delas chegando à sofisticação tecnológica do uso do computador e do geoprocessamento, detectam necessidades da óptica dos investigadores. Complementam-se com técnicas qualitativas, através de grupos focais com líderes das comunidades, tratando de problematizar as necessidades.

Confesso que sempre me agradou essa maneira, quase esquemática, de pensar a medicina social, ou a saúde na sociedade, se quisermos ser mais modernos. Os problemas; os métodos ou propostas para enfrentá-los; e a própria organização dos serviços que a sociedade cria para aplicar os métodos com vistas a resolver os problemas; todos eles admitem abordagens individuais e/ou coletivas. Não é este o momento para retomar essa temática do individual e do coletivo ou, se quisermos, do clínico e do epidemiológico, ou ainda do privado e do público.

É evidente que a proposta do livro de McKeown \& Lowe torna-se tanto mais precisa, quanto mais concreta é a realidade com que nos defrontamos. Quero dizer que, considerando uma pequena comunidade, o esquema de pensamento implícito na proposta permite dimensionar cada um desses três eixos de maneira mais precisa. Para realidades mais complexas, a situação muda muitas vezes de maneira dramática. E o sistema de saúde é complexo na sua essência (Tarride, 1998). 


\section{Macropolíticas em saúde para o decênio}

A crise da saúde pública tem sido intensamente abordada pela Organização Mundial da Saúde (OMS), especialmente após a mudança de seu diretor geral em meados de 1998. A Organização Pan Americana da Saúde (Opas), promoveu também intenso debate sobre esta crise em anos recentes (OPS, 1992; OPS, 1993).

Numa primeira aproximação, creio que devemos nos valer do que tem constituído o debate principal atualmente em todo o mundo: a crise da saúde pública, enfaticamente abordada pela OMS e por suas agências regionais. Na região das Américas, a Opas/OMS, em documentos próprios ou em parceria com a Cepal, faz um contraponto importante às propostas do Banco Mundial (BM). Ao dizer isso, identificamos pelo menos duas vertentes de análise que devem ser seguidas se quisermos estar inseridos no debate relevante. Claro que, do ponto de vista metodológico, existem inúmeras propostas que merecem destaque. Entre elas o movimento da Construção de Cenários e Estudos Futuros, com vários grupos em todo o mundo, em particular o sediado em Genebra, na OMS, do qual faz parte um punhado de brasileiros. Tem primado por veicular os interesses de um novo tipo de profissional, geralmente oriundo da área de engenharia ou administração, com forte embasamento em informática e modelos matemáticos. Embora participante desse grupo, não creio que seja o momento de recorrermos a essa técnica de prospeção, pelo menos num primeiro momento. Reunião realizada em Montevidéu, em junho de 1996, sobre Tendências Futuras e Renovação da Saúde para Todos pode ser tomada como exemplo dos riscos que corremos ao incluirmos acriticamente tais modernidades no debate num momento muito precoce. Em todo o caso, vale a menção. Os maiores esforços nesse sentido, de estudos futuros na área da saúde, têm sido desenvolvidos pela OMS em Genebra; ver, por exemplo WHO (1993) e diversas publicações subseqüentes do mesmo grupo e, em particular da Rifs (La Red Internacional de Futuros de Salud).

\section{As comunidades epistêmicas}

Muito mais interessante do que a menção a essas tecnologias sofisticadas e sem grande substância é uma tendência que se verifica no âmbito da sociologia política: a introdução de uma abordagem pelo conceito de comunidade epistêmica, para dar conta da complexidade do processo de implementação de políticas públicas. A comunidade epistêmica não é composta exclusivamente de cientistas, o que a diferencia da comunidade científica propriamente dita, com seu consenso paradigmático intersubjetivo, 
na linha proposta por Thomas Khun. Assemelha-se mais aos coletivos do pensamento, grupos sociológicos com um estilo de pensamento comum, identificados por Ludwig Fleck, um precursor de Khun (Haas, 1992).

A comunidade epistêmica, nessa formulação, é composta por profissionais, inclusive cientistas, mas também por políticos, empresários, banqueiros, administradores, entre outros, que trabalham com um bem fundamental: o conbecimento como instrumento de implementação de politicas. Os membros de uma comunidade epistêmica compartilham valores e têm um projeto político fundado nesses valores. Compartilham, ainda, maneiras de conhecer, padrões de raciocínio e compromissos com a produção e aplicação do conhecimento.

Os exemplos no âmbito da política econômica são superabundantes. Basta ver os últimos acontecimentos, de fevereiro de 1999, envolvendo a presidência do Banco Central do Brasil. Existem, evidentemente, correntes em litígio. Indicado como o novo presidente do Banco Central, Francisco Lopes, em sua sabatina no Senado, virgulou suas frases com repetidos vis a vis. Daí a uma semana deram-lhe um verdadeiro vis a tergo: "sai da frente que atrás vem gente". Foi sumariamente demitido e seu lugar ocupado por especulador do grande mercado financeiro internacional. $\mathrm{O}$ ministro do Planejamento do Brasil deixa o governo e vai assumir diretoria no BID. Discute-se a quarentena dos dirigentes do setor da alta finança pública: ao abandonarem seus cargos passariam alguns meses proibidos de trabalhar em sua profissão no setor privado; evidentemente, remunerados pelo setor público. Como se a questão central fosse operar no mercado de capitais e não a pertinência a esta ou aquela corrente de pensamento econômico. Jeffrey Sachs, economista de prestígio de Harvard, afirma que Michel Camdessus, presidente do FMI, não tem credibilidade internacional e deveria pedir desculpas ao Brasil pelos erros a que nos está induzindo. Parece ser consenso internacional que estamos sendo dirigidos de fato por uma determinada comunidade epistêmica. Ocorre-nos pensar no velho Karl Marx, torcido de ódio na sepultura, tal é o chorrilho de asneiras que se tem dito a respeito dos consensos de empregados e patrões contra o governo. Como se o Estado fosse um personagem do teatro grego, com sua máscara de tragédia, e não resultado de um pacto de dominação. Imaginamos se não há quem seja capaz de recuperar, adaptando à vida moderna, o clássico Salário, preço e lucro? Imaginamos, ainda, que esta idéia nos remete à conclusão que uma comunidade epistêmica também é composta de figuras históricas, como Marx.

Também na saúde há circulação de quadros de administração superior do Ministério e de Secretarias de Saúde para as agências internacionais. 
Diversos brasileiros já exerceram cargos relevantes de direção, tanto na OMS, quanto na Opas. Há uma nítida diferença que faz com que fiquem pasmos nossos companheiros na América Latina e em Washington, quando dizemos que no Brasil quase ninguém sabe quem são os brasileiros com prestígio internacional nas Agências da ONU da área da saúde. E que eles raramente têm chance para ocupar um cargo de ministro.

Com relação à implementação da política de saúde, na atualidade, identificam-se duas correntes, com paradigmas conceituais distintos: o da saúde pública e o da economia da saúde. O paradigma da saúde pública adota o princípio da eqüidade e o marco conceitual da epidemiologia. $\mathrm{O}$ paradigma da economia da saúde, os princípios da competitividade, da focalização e seletividade da ação pública e o método das ciências econômicas e administrativas. Identificam-se como principais agências de formulação desses paradigmas, respectivamente, a Organização Mundial da Saúde (OMS) com suas regionais e o Banco Mundial (Melo \& Costa, 1994).

O pensamento da comunidade financeira, ou do stablishment, como a chama Vicente Navarro, sempre se expressou de forma muito clara, influenciando fortemente o discurso dos sanitaristas. Em contundente artigo, publicado há 15 anos, o fero espanhol de Johns Hopkins já denunciava que o discurso de Alma-Ata nada era senão uma adaptação à área da saúde da proposta neoliberal do Relatório da Comissão Willy Brandt, que tratou dos interesses dos países ricos (Navarro, 1984).

No momento atual a comunidade da saúde pública tenta heroicamente salvar Alma-Ata e a proposta de Saúde Para Todos até o ano dois mil (SPT /2000). Reciclar a proposta atrai a maioria dos esforços, em todos os quadrantes. Já se fala não somente em SPT: agora deve ser Saúde Para Todos com Eqüidade. Mencionamos apenas algumas das contribuições mais recentes, quase sempre associadas à idéia de cenários e de estudos futuros, como já assinalamos: WHO (1994), Revisitando Alma-Ata; Focal (1995), Cenários "canadenses" para as Américas; van de Water \& van Herten (1996), Avaliação holandesa das metas de SPT da OMS na Europa; WHO (1996), Tendências futuras da SPT na Europa; STG (1996), Cenários em saúde pública e em atenção médica; PAHO (1998), Renovar a SPT nas Américas; OMS (1998), Perspectivas para a saúde mundial no século XXI.

Por sua vez, a comunidade da economia da saúde gravita ao redor de uma importante publicação do Banco Mundial, Investindo em saúde, introduzindo o conceito de carga da doença em contraponto aos usuais indicadores de saúde dos sanitaristas. Propondo uma cesta básica de ações típicas do Estado (geralmente com forte conteúdo de externalidades positivas como 
a vacinação e o saneamento do ambiente) e a focalização de ações concentradas em grupos mais vulneráveis. Contempla supremacia do mercado nas demais ações estimulando a competitividade, como é chamada a privatização dos serviços em algumas das versões do documento. É curioso notar que o documento básico, em inglês, World development report 1993: investing in health $(\mathrm{WB}, 1993)$ difere, nesse sentido, da versão francesa.

\section{A OMS sob nova administração: o século XXI}

Nesta incursão pelo terreno do futuro imediato, vou me restringir a listar algumas referências sem a pretensão de esgotar o assunto, que é muito mais rico, tanto na literatura internacional, quanto na nacional. Vou detalhar apenas a contribuição que considero mais relevante para a proposta de traçar novos rumos para macropolíticas de saúde no decênio. Trata-se do discurso de posse da nova diretora geral da OMS, Dra. Gro Harlem Brundtland (1998), pelo que representa de uma grande expectativa de mudança em nível internacional, especialmente no que diz respeito à reinclusão da saúde na agenda mundial do debate contemporáneo.

A nova diretora, em julho de 1998, ao tomar posse anunciou sua equipe e sua disposição de:

- construir, com as demais agencias da ONU, maneiras criativas de unir esforços em busca da saúde, do desenvolvimento e da redução da pobreza;

- buscar o suporte da sociedade civil, do setor privado e da comunidade científica e de saúde.

No sentido de atingir seu objetivo principal (WHO must be one, not 50 programmes working separately) agrupou todos os programas e atividades existentes em conglomerados (clusters). A simples visão dos conglomerados nos dá uma boa idéia do que constitui a essência do debate atual e, portanto, de qualquer esforço de prospecção. Os conglomerados são agregados em quatro grandes eixos e nove clusters:

- populações e comunidades saudáveis (três clusters)

- desenvolvimento sustentável e ambiente saudável;

- família e serviços de saúde (incluindo desenvolvimento de sistemas e melhoria da qualidade de serviços de saúde);

- mudança social e saúde mental (incluindo o impacto do envelhecimento sobre o sistema de saúde, mudanças sociais e demográficas); 
- combate a doenças (dois clusters)

- doenças transmissíveis (respostas efetivas, especialmente para doenças emergentes e re-emergentes);

- doenças não transmissíveis (discussão da capacidade de tratamento do sistema e dos serviços e de sua função de advocacy em busca de mudanças no comportamento);

- manutenção da saúde (sustaining health) (dois clusters)

- evidências e informações para definição de políticas (no sentido de alcançar: eqüidade, custo/efetividade e qualidade);

- tecnologia em saúde e drogas, inclusive vacinas (influenciar o desenvolvimento, a qualidade, o custo e a distribuição de tecnologias e drogas buscando impactos positivos na saúde da população);

- relações externas e suporte (dois clusters)

- esforços no sentido de fazer a WHO e a saúde mais visíveis no contexto mundial tanto em seu relacionamento com as demais agências da ONU quanto na garantia de suporte à nova organização da OMS em clusters e a necessária articulação entre eles.

\section{O Brasil tem uma proposta (ah! se tem)}

A situação nacional merece a mesma análise feita em nível internacional, incluindo a questão da dívida, dos ajustes e a crise internacional do mercado financeiro na qual estamos imersos até a raiz dos cabelos. Há, no entanto, na área da saúde uma peculiaridade: a Constituição de 1988 previu um Sistema Único de Saúde (SUS), universal, com integralidade das ações, descentralizado e participativo mediante controle regulamentado pela sociedade. Acreditam muitos que foi celebrado um pacto social na década de 80 na área da saúde. A VIII Conferência Nacional de Saúde (1986) deu fundamentação ao capítulo da saúde na Constituição (1988) e à Lei Orgânica da Saúde, ou Lei do SUS (Lei 8080, de 1990). Não seria exagero admitir que a comunidade epistêmica da saúde pública brasileira conseguiu uma vitória expressiva durante o processo constituinte. É sempre bom recordar que, apesar de convocada pelo presidente José Sarney, a VIII Conferência não contou com a presença dos representantes da iniciativa privada na cota a eles atribuída. O Relatório da Conferência remetia a uma Comissão Nacional da Reforma Sanitária (CNRS), a responsabilidade de produzir um texto mais compatível com a necessária pactuação com 


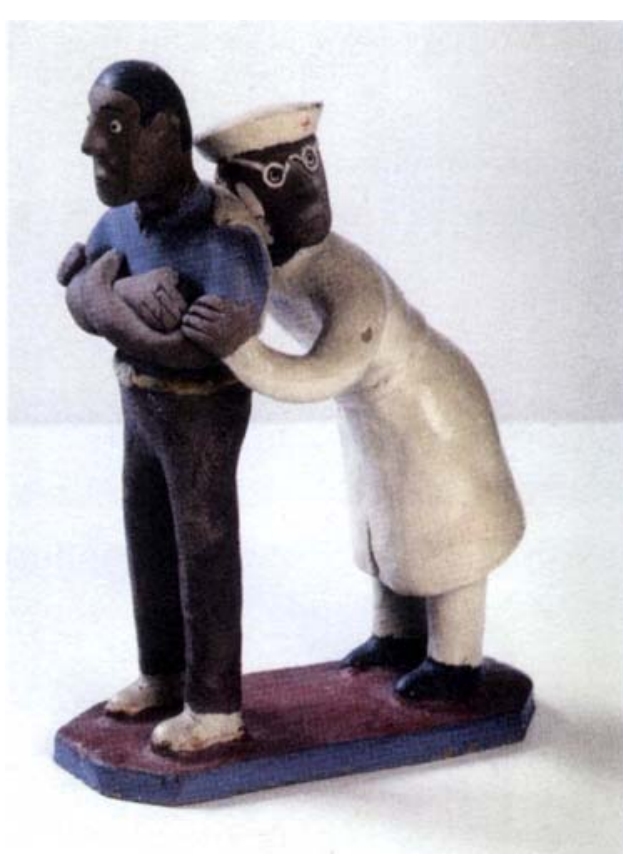

Zé Caboclo

Exame (1955)

Barro queimado e pintado

Altura $19 \mathrm{~cm}$

Coleção Van de Beuque

os setores privados mais ativos e com o centrão, que representava esses interesses na Assembléia Nacional Constituinte. O texto foi considerado polêmico para muitos por abrir espaço à iniciativa privada, ainda que $\mathrm{em}$ caráter complementar. Setores mais radicais da comunidade dos sanitaristas consideraram que o texto encaminhado, por fim, à Assembléia Nacional Constituinte burlava as decisões da VIII Conferência. Na verdade, a comunidade científica deu seu aval ao texto de consenso. Estive, pessoalmente, como depoente perante a Subcomissão de Saúde, Seguridade e Meio Ambiente da Assembléia Nacional Constituinte. Quando o presidente, deputado Elias Murad, me deu a palavra disse, inflando o peito: A ciência brasileira apoia o relatório da CNRS. Falava em nome da SBPC e apontei o Relatório impresso que tinha sido colocado, por nossos lobbistas numa mesinha ao lado da porta de entrada do auditório. Creio que nesse momento expressava o pensamento de uma comunidade epistêmica, envolvendo não apenas os cientistas da SBPC.

Passados apenas dez anos da aprovação da Lei do SUS (8080), a situação atual impõe a necessidade imperiosa de novo pacto que dê conta das mudanças decorrentes dos fantásticos esforços de implantação do SUS e da emergência dos novos atores econômicos na área da saúde: os seguros privados, os planos de saúde e sua regulamentação. Mediante as Normas Opera- 
cionais Básicas (NOB/93 e NOB/96) e os mecanismos de compensação - as Comissões Intergestoras Tripartite (nacional) e as Bipartites (estaduais) - o Estado brasileiro procura desesperadamente implantar o SUS Constitucional. Procura, ainda, resolver a questão do financiamento, questionando: o orçamento da seguridade social (OSS) e sua deturpação; a discussão da Proposta de Emenda Constitucional (PEC 169) que regulamenta a atribuição de recursos marcados para a saúde nos três níveis de governo; e o remendo representado pela CPMF. Quanto ao controle social, os Conselhos e as Conferências de Saúde, em todos os níveis são uma experiência impar que talvez deva ser considerada como o mais importante exemplo brasileiro de participação na atualidade. A sociedade ainda não se deu conta de

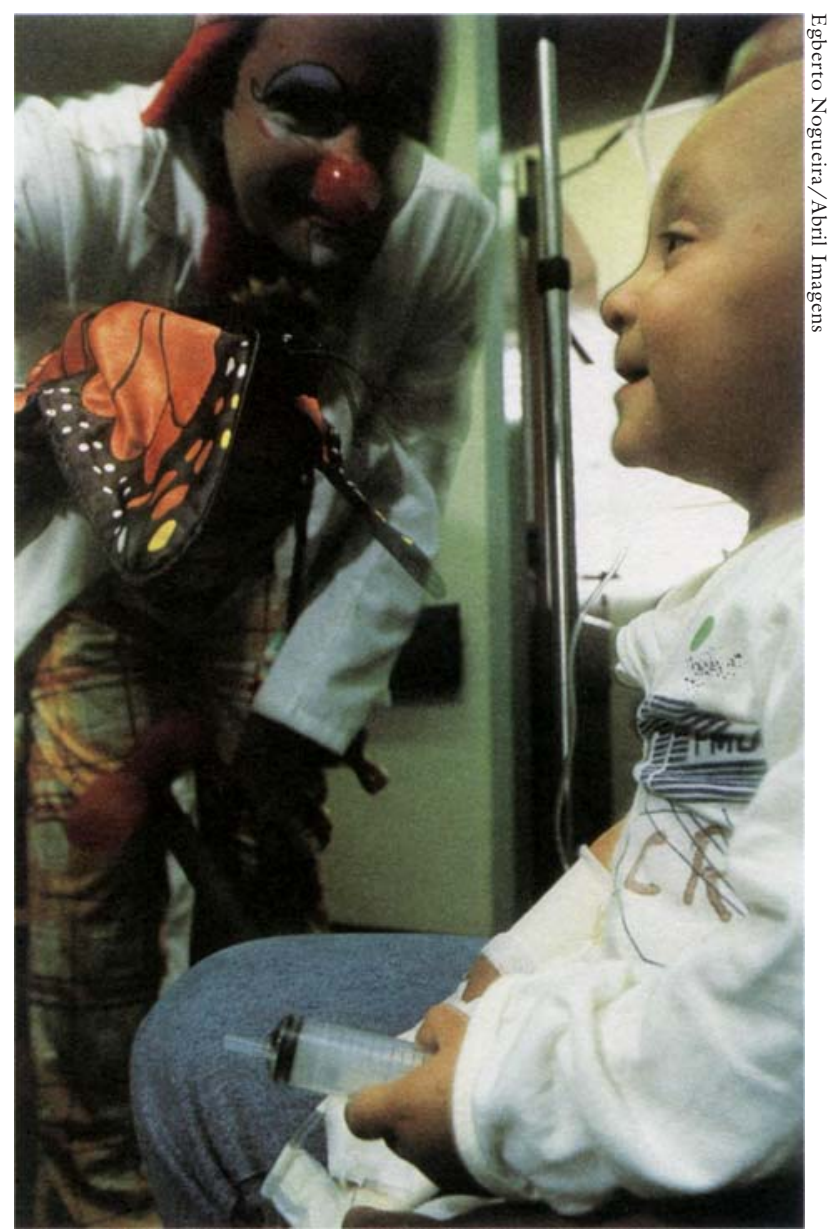

Criança em tratamento no Hospital das Clínicas, SP seu potencial indutor de participação e controle social.

Deixo de aprofundar-me nas características do SUS, suas dificuldades e seus sucessos. Certamente serão o ponto nodal dos demais artigos e depoimentos deste Dossiê Saúde.

\section{Carta aberta ao diretor da Opas}

O diretor da Organização Pan-Americana da Saúde (Opas/OMS), George Alleyne (1998), em visita ao Brasil, concedeu entrevista ao jornal Folha de S. Paulo, na qual, segundo interpretação do sanitarista Gilson Carvalho (1998), nada mais fez do que "recitar a cartilha do FMI para o pobre Brasil subdesenvolvido". Disse Alleyne:

"Defendo o fim da gratuidade nos serviços de saúde, em todos os níveis. O governo deveria oferecer gratuitamente uma "cesta básica" de ser- 
viços de saúde para toda a população, composta de consultas ambulatoriais, vacinação e programas de saneamento . Os procedimentos mais complexos (como transplantes e cirurgias cardíacas) deveriam ficar por conta da iniciativa privada cabendo ao Estado financiar apenas o tratamento da população de baixa renda. O Governo deve assumir a responsabilidade apenas sobre os serviços básicos. Nos serviços mais sofisticados o Estado tem de garantir que pessoas desfavorecidas tenham acesso" (Folha de S. Paulo,14 dez. 1998).

Indignado, Gilson Carvalho fez circular uma Carta aberta ao Diretor da Opas, na qual enfatiza que:

“Muitos questionam porque não passarmos de papel passado o país para o FMI. Afinal é ele quem há muito tempo já dita o que fazermos! Agora estamos diante de uma santa aliança. Dão-se as mãos o Diretor da OPAS e o FMI. Olhe, seu Alleyne, quando voltar ao Brasil, procure antes conhecer nossa realidade, e ver se dá para recitar sua cartilha neo-liberal. Temos uma Constituição em que o Direito à Saúde é garantido como Dever do Estado, não como alguém bonzinho que oferece saúde gratuitamente para seu povo. O povo paga contribuições sociais específicas para a área da seguridade social, incluindo a saúde. Paga e paga bem e sempre com aumentos como a da CPMF. O brasileiro, na sua Constituição optou por construir um Seguro Público e Solidário para garantir sua saúde través da montagem de um Sistema Único de Saúde. Desobrigar o Estado de se responsabilizar pela saúde de todos é um desrespeito à Constituição. Não bastasse isto, teria efeitos catastróficos sobre pobres e ricos. Não me venha dizer, Alleyne, que o rico deve cuidar de sua saúde e deixar os pobres para receber 'gratuitamente' uma medicina de pobre para pobre. Hoje no nosso pacto solidário de financiamento da saúde, os que mais têm contribuem em números absolutos com mais, ainda que com o mesmo percentual (seria melhor se não houvesse sonegação). Você propõe que o Governo brasileiro diga a eles que paguem de novo seus próprios serviços de saúde. No dia seguinte estarão todos na Justiça solicitando devolução do que contribuem para que o Estado garanta sua saúde! E aí, com que dinheiro se financiará a saúde dos que menos têm? Exclusivamente com sua contribuição que, em números absolutos, é pífia? Nosso problema de saúde é bem outro: governos que não cumprem a lei e, no pós constitucional, foram contumazes em desviar recursos da saúde para outras áreas. Agora, Alleyne, vir aqui para prestar este desserviço aos que lutam há décadas pelo direito Universal à saúde, é fazer o discurso do inimigo. Dos privatizantes. Da economia de mercado, ótima para os que têm e péssima para os que não conseguem ter. Resta-nos ainda uma esperança: este dito infeliz é só seu, ainda não é a opinião oficial da OPAS. Vade retro, Alleyne. Aliados iguais a você não precisamos, nem queremos." 


\section{A multiplicidade dos desafios}

Reinterpretando o Postulado de coerência do sanitarista e pensador argentino Mário Testa (1992) à luz do eixo aqui empregado, diríamos que a identificação dos problemas, os métodos propostos e os serviços criados devem ser coerentes. Claro que todas estas dimensões do processo precisam ser encaradas em sua complexidade histórica, geográfica e temporal (de curto prazo). Em cada caso, a questão do poder deve estar sempre à vista. O poder técnico, o poder político e o poder administrativo. É mais fácil conceber o postulado em realidades concretas, no nível local. No entanto é no nível global que fatalmente se encontrarão determinações a que se deve dar um valor supremo na compreensão do que se passa com a saúde. É também neste nível macro que devem ser buscadas as propostas de organização do sistema de saúde. Uma abertura do mercado de planos de saúde à iniciativa privada internacional projeta o surgimento de mecanismos de constrangimento na implementação do SUS que dificilmente poderão ser contornados. Basta ver o que está ocorrendo com nossa maior empresa pública, a Petrobrás, ameaçada de privatização, após a quebra do monopólio de exploração do petróleo.

Em sua sagrada indignação, Gilson Carvalho recicla as idéias de Vicente Navarro, 15 anos depois, e faz-nos lembrar o compositor Vinícius de Moraes em seu Olha aqui Mr. Buster, verdadeiro poema em prosa. Vinícius era ainda diplomata, secretário de Consulado e, numa festa, confessou a Mr. Buster, verdadeiro Wasp, pelo que se depreende da crônica genial, que se estava preparando para voltar definitivamente para o Brasil. Espantado, o americano pôs-se a elogiar os avanços tecnológicos que seriam deixados para trás para viver na medíocre Latin America, o que era definitivamente incompreensível. Na resposta, Vinícius, concorda que vai sentir deixar os benefícios de "vacuum cleaners com muito maior poder de chupo que um beijo de Marilyn Monroe. Mas, olha aqui Mr. Buster, sabe lá o que é ter uma jabuticabeira no quintal, um choro do Pixinguinha e torcer pelo Botafogo?”

Nunca é demais lembrar o que representa Gilson Carvalho no cenário da saúde pública no Brasil. Secretário Municipal de Saúde de São José dos Campos, por mais de uma vez, deu sua contribuição maior quando atuou na Secretaria Nacional de Assistência à Saúde, do Ministério da Saúde, em 1993. Compôs, então, o Grupo Especial de Descentralização (GED) ao qual se deve a elaboração da Norma Operacional Básica NOB/93, responsável pelo principal salto na implementação do processo de municipalização da saúde. Não por acaso, a NOB/93 intitula-se Descentralização das açõese serviços de saúde: a ousadia de cumprir e fazer cumprir a lei (Brasil, 1993). 
A questão, no caso da indignação de Gilson Carvalho contra a entrevista do diretor da Opas, é, no entanto, lamentavelmente mais séria. Não se trata, simplesmente de ironizar os misters que nos queiram ensinar o que fazer, como se tratassem com fedelhos. A experiência com o setor econômico/financeiro mostra como num mundo globalizado as forças de mercado adquirem uma hegemonia quase impossível de superar no marco dos modelos impostos pelas agências multilaterais e pelo G-7. O que nos resta, então? Nosso SUS não é prosaico e delicioso chorinho, ou suculenta jabuticaba sabará. Também não é estrela solitária como a da camiseta do glorioso Botafogo: são inúmeras, em todo o mundo, as alternativas contrapostas aos desígnios do Banco Mundial na área da saúde; não estamos escoteiros. A defesa do SUS e seus princípios básicos, inseridos na Constituição, deverão ser preservados se quisermos seguir com uma experiência fascinante de envolvimento da sociedade brasileira na conquista de um sistema de saúde fundado nos princípios éticos do humanismo e da solidariedade. Num momento em que o ministro da Saúde é um economista, surpreendentemente sensível às idéias da comunidade epistêmica dos sanitaristas, só nos resta esperar que ele seja definitivamente contaminado por esta loucura branda que nos fez optar pelos pobres e pela pobreza na perseguição de um ideal.

Referências bibliográficas

ALLEYNE, G. Entrevista ao jornal Folha de S. Paulo, 14 dez. 1998.

BERLINGUER, G. Con i lettori, Qualità Equità, rivista del welfare futuro, n. 1, p. 5-15, gen./mar. 1996.

[neste número].

Globalização e saúde global. Estudos Avançados, n 35, 1999

BRASIL, Ministério da Saúde, Sistema Único de Saúde. NOB 01/93 - Descentralização das ações e serviços de saúde: a ousadia de cumprir e fazer cumprir a Lei. Brasília, DF, 1993.

NOB 01/96 - Gestão plena com responsabilidade pela saúde do cidadão. Brasília, DF, 1997.

BRUNDTLAND, G.H. Address to WHO staff. Discurso de posse, em 21 de julho de 1998.

CARVAlHO, G. Carta aberta ao diretor da Opas, distribuição pela Internet e amplamente divulgada entre os sanitaristas brasileiros, 1998. 
FOCAL. Cual futuro para las Américas ? Cuatro escenarios. Fundación Canadiense para las Américas, 1995, ISBN 1-896301-08-8.

HAAS, P.M. Knowledge, power, and international policy coordination introduction: epistemic communities and international policy coordination. International Organization, v. 46, n. 1, p. 1-35, 1992.

McKEOWN, T. \& LOWE, C.R. An introduction to social medicine. Oxford and Edinburgh, Blackwell Scientific Publications, 2 ${ }^{\text {nd }}$. printing, 1968.

MELO, M.A.B.C. \& COSTA, N.R. Desenvolvimento sustentável, ajuste estrutural e política social: as estratégias da OMS/OPS e do Banco Mundial para a atenção à saúde. Planejamento e Políticas Públicas, Ipea, n. 1, p. 49-108, jun./ dez. 1994.

NAVARRO, V. A critique of the ideological and political position of the Brandt Report and the Alma-Ata Declaration. International J. Hlth. Services, v. 14, n. $2,1984$.

OMS. Rapport sur la santé dans le monde, 1998: La vie au $21^{e}$. siècle, Une perspective pour tous. Genève, OMS, 1998. ISBN 9242561894.

OPS. La crisis de la salud pública: reflexiones para el debate. Washington, DC, OPS, Publicación Cientifica n. 540, vi, 1992, 280 p.

OPS. Sobre la teoría y práctica de la salud pública: un debate, multiples perspectivas. Washington, DC, OPS, Serie Desarrolo de Recursos Humanos n. 98, viii, 277 p.

PAHO. National strategies for renewing health-for-all. Technical report. Washington, DC, 1998. PAHO/DAP/98.3.39.

RIFS. La red internacional de futuros de salud. Folheto de lançamento. Contato nas Américas: Nancy Decia. San Francisco, CA, USA, s.d. FAX: (1) 415/3569300 .

STG. Scenario development and costing in health care. STG-Foundation for Future Health Scenarios Utrech (The Netherlands), International Books, 1996. ISBN 9062248772 .

TARRIDE, M.I. Saúde pública: uma complexidade anunciada. Rio de Janeiro: Editora Fiocruz, 1998.

TESTA, M. Pensar em saúde. Porto Alegre, Artes Médicas/Abrasco. 1992.

Van de WATER \& van HERTEN. Bull's eye or Achilles' heel: WHO's European health for all targets evaluated in the Netherlands. Leiden (The Netherlands), TNO Prevention and Health, 1996. ISBN 9067434329.

WB. World development report: investing in health. Washington, DC, World Bank/ Oxford University Press, 1993. 
WHO. Health futures in support of healt-for-all. Geneve, WHO, off-set document, 1993.

Primary health care concepts and challenges in a changing world:

Alma-Ata revisited. Geneva, WHO/SHS/CC/94.2, 1994.

Third consultation on future trends and the European HFA

strategy. Copenhagen, WHO-EUR/ICP/EHFA 94 01/MT01. 1996.

RESUMO - O TRABALHO DÁ ênfase à natureza econômica da saúde num momento em que o setor terciário da economia é o que mais cresce e a área da saúde é de todas a mais dinâmica. Aborda a crise da saúde pública considerando seus problemas, métodos e serviços. Adota o conceito de comunidade epistêmica para a análise da situação atual. Identifica duas correntes, com paradigmas conceituais distintos - o da Saúde Pública e o da Economia da Saúde. As principais agências de formulação desses paradigmas são, respectivamente, a Organização Mundial da Saúde e o Banco Mundial. No plano nacional, lembra que a Constituição de 1988 previu um Sistema Único de Saúde (SUS) universal, com integralidade das ações, descentralizado e participativo, com controle social. O SUS vem sendo implementado através de Normas Operacionais e dos mecanismo de compensação representados pelas Comissões Intergestores. Questão ainda não totalmente resolvida é a do financiamento do SUS.

ABSTRACT - THIS PAPER emphasizes the economic nature of health care at a time when the tertiary sector is the one fastest growing in economy and health care is the most dynamic. It touches upon the public health crisis considering health problems, methods and services. The epistemic community concept is used to analyse the current situation. Two trends are identified, exhibiting distinct conceptual paradigms: one in Public Health, the other in Health Economics. The main agencies for the formulation of those paradigms are, respectively, the World Health Organization and the World Bank. On the national level, the 1988 Constitution provided a universal Unified Health System (SUS - Sistema Unificado de Saúde), complete in its activities, decentralized and fully engaged, under social control. The SUS has been established according to the Operational Rules and the compensation mechanisms represented by its Intermanaging Committees. An issue not yet fully settled is the SUS finacing.

José R. Carvalheiro é médico, formado pela Faculdade de Medicina da USP em 1961, professor titular de Medicina Social da Faculdade de Medicina de Ribeirão Preto da USP, colaborador-pleno do IEA-USP e diretor do Instituto de Saúde da Secretaria de Estado da Saúde de São Paulo. 